\title{
BUKU AUDIO SASTERA SEBAGAI ALTERNATIF PEMBACAAN KARYA SASTERA DALAM ERA DIGITAL
}

(LITERARY AUDIOBOOKS AS ALTERNATIVE

READING MATERIAL IN THE DIGITAL ERA)

Madiawati Mamat@Mustafa

atie@um.edu.my

\author{
Tengku Intan Marlina Tengku Mohd. Ali \\ inmarlin@um.edu.my
}

Nurhamizah Hashim

aeee@um.edu.my

Nur Asyirah Hazari

nurasyirahharzari95@gmail.com

Universiti Malaya, Kuala Lumpur

Malaysia

Received: 21 Februari 2020; Accepted: 8 April 2021

\begin{abstract}
Audiobooks are one of the many mediums for the delivery of literary works in the digital age. However, audiobooks have existed since 1931. For example, the American Foundation for the Blind and the Library of Congress would provide audiobook-based programmes for the visually impaired. The use of this particular medium in Malay literature is still not considered widespread. After that, audiobooks started to flourish in the field of early childhood education and currently, there is a publishing company that produces audiobooks in Malaysia. However, its existence and evolution in literature are not widely known than to literary works delivered through other new media. This study, funded by the faculty grant GPF006K-2018, examined the various forms of literary audiobooks published by the company Nusantara as a means to provide alternative reading material in Malaysia. This study aimed to identify and discuss the history and development of literary audiobooks in Malaysia to highlight their form and importance in the digital era. This study utilised text analysis to examine past research on audiobooks and analysed various


literary audiobooks available in the market. Additionally, interviews were conducted with different publishers to get their feedback regarding the general acceptance of such material amongst their customers. Findings showed that Nusantara Audiobooks actively publishes literary audiobooks, be it from Malaysia or Indonesia. In conclusion, these digital materials in the market would diversify reading methods and analyse literary works.

Keywords: audiobooks, Malay literature, digital, alternative, evolution.

\begin{abstract}
Abstrak
Buku audio merupakan salah satu medium penyampaian karya sastera dalam era digital, walaupun buku audio sejak tahun 1931 lagi, iaitu apabila pihak American Foundation for the Blind and Library of Congress Book mengadakan program buku audio untuk projek orang-orang cacat penglihatan, penggunaan medium ini dalam bidang kesusasteraan Melayu masih belum meluas sehingga hari ini. Selepas itu kaedah buku audio mula berkembang dalam pendidikan awal kanak-kanak dan kini di Malaysia terdapat syarikat penerbitan yang ada menerbitkan karya sastera dengan menggunakan medium buku audio. Namun begitu keberadaan buku audio dan perkembangannnya dalam bidang kesusasteraan tidak diketahui secara meluas sebagaimana karya sastera dalam media baharu yang lain. Justeru itu, kajian daripada hasil penyelidikan geran program fakulti (GPF006K-2018) ini akan meneliti bentuk-bentuk buku audio sastera yang diterbitkan oleh Syarikat Nusantara audiobooks sebagai alternatif bahan bacaan sastera di Malaysia. Objektif kajian ini akan mengenal pasti dan membincangkan sejarah dan perkembangan buku audio sastera di Malaysia bagi memperlihatkan bentuk dan kepentingannya dalam era digital. Kajian yang menggunakan kaedah analisis teks ini akan meneliti kajian-kajian lepas berkenaan dengan buku audio dan meneliti buku-buku audio sastera yang berada di pasaran. Dapatan kajian mendapati bahawa syarikat Nusantara audiobooks merupakan badan yang aktif menerbitkan buku-buku audio sastera, sama ada karya sastera Malaysia dan Indonesia. Keberadaan buku audio sastera dalam pasaran yang menggunakan media digital dapat mempelbagaikan kaedah pembacaan dan penelitian karya sastera.
\end{abstract}

Kata Kunci: buku audio, digital, sastera Melayu, alternatif, perkembangan.

\title{
Pengenalan
}

Buku audio merupakan buku yang berbentuk suara yang dirakam oleh seorang pencerita. Buku ini boleh diakses oleh khalayak pada bila-bila masa dengan menggunakan pelbagai peralatan elektronik dan teknologi seperti radio, pita rakaman, telefon pintar ataupun komputer. Buku-buku berbentuk rakaman suara telah meluas dipasarkan secara dalam talian. Namun begitu, buku audio dalam bidang kesusasteraan Melayu masih baru bertapak dan kurang dikenali serta digunakan secara meluas. Hal ini kerana keberadaan buku-buku dalam penerbitan buku audio kesusasteraan Melayu terhad kepada karya-karya yang tertentu sahaja. Ini dapat dilihat daripada sorotan kajian, iaitu masih belum terdapat kajian-kajian yang membincangkan tentang buku-buku audio karya kesusasteraan Melayu.

Buku audio merupakan gabungan dua kata, iaitu buku yang merupakan kepingan helaian bertulis yang diikat menjadi satu unit. Audio pula bererti suara. Oleh itu, buku audio boleh 
didefinisikan sebagai sebuah buku yang diversikan dalam bentuk audio audiobooks dan terdapat pembaca yang membaca buku tersebut kemudian dirakam dalam bentuk suara. Kebiasaannya, buku audio adalah sama isinya dengan teks asal daripada buku. Namun begitu, pengolahan kata dengan bahasa verbal dapat menjadikannya lebih menarik jika diolah secara kreatif supaya tidak membosankan pendengar. Buku audio kini masih asing dalam kalangan masyarakat. Bagi mereka yang memiliki kekurangan penglihatan (buta), buku ini merupakan salah satu alternatif untuk mereka menikmati isi buku dengan mendengar. Namun begitu, bacaan melalui huruf braille lebih menjadi pilihan. Bagi mereka yang normal pula, mereka lebih cenderung untuk membaca buku secara langsung kerana tidak semua buku mempunyai versi audio.

Buku audio digunakan dengan memuatkan suara-suara dengan pelbagai nada yang sesuai dengan jenis karya yang dirakamkan. Baskin dan Harris (1995, p. 372) ada menyatakan bahawa konsep buku audio adalah seperti kesusasteraan awal dahulu, iaitu "first literature was heard, not read". Oleh itu, hal ini sangat membantu sebagai bahan bacaan alternatif kepada masyarakat yang sibuk dengan urusan harian, tetapi masih mahu mencari peluang untuk membaca. Oleh yang demikian, penyelidikan ini dijalankan bagi mengenal pasti dan membincangkan bentuk dan perkembangan buku audio sastera di Malaysia bagi memperlihatkan fungsi dan kepentingannya dalam era digital dengan memberikan tumpuan kepada syarikat penerbitan Nusantara Audiobooks.

\section{Sorotan Kajian}

Hasil daripada penelitian, terdapat beberapa buah kajian yang telah dilakukan dan relevan dengan kajian ini. Justeru, dalam mencari maklumat mengenai buku audio, terdapat beberapa kajian lepas yang telah dilakukan berkaitan dengan bidang kajian ini.

Kajian yang berjudul Pembangunan Perisian Interaktif Audio Buku Pendidikan Islam Sekolah Menengah Kebangsaan (i-TALK PISMEN): Satu Kajian Keperluan Bagi Murid Berkeperluan Khas Masalah Penglihatan telah dilakukan oleh Nurutthoilah Mohd Nabil, Noornajihan Jaafar, Norakyairee Mohd Raus, Nursyahirah Wahidah Masrom dalam International Journal for Studies on Children, Women, Elderly and Disabled, Vol. 4, pada Jun, 2018. Kajian ini dilakukan bagi meninjau keperluan pembangunan Perisian Interaktif Audio Buku Pendidikan Islam Sekolah menengah Kebangsaan (i-TALK PISMEN) bagi Murid Berkeperluan Khas (MBK MaL) Masalah Penglihatan. Kajian ini mengaplikasikan pendekatan kualitatif dengan menggunakan kaedah temu bual terhadap dua orang OKU penglihatan dan seorang guru sekolah pendidikan khas. Selain itu, kajian ini juga menggunakan kaedah kuantitatif dengan pengedaran borang kaji selidik kepada kumpulan murid Tingkatan 1 di Sekolah Menengah Pendidikan Khas Terengganu. Secara keseluruhan, kajian mendapati bahawa pembangunan buku audio Pendidikan Islam sangat bermanfaat dan membantu murid berkeperluan khas yang mempunyai masalah penglihatan. Hasil kajian ini menunjukkan bahawa pembangunan i-TALK PISMEN sangat diperlukan bagi membantu sesi pengajaran dan pembelajaran (P\&P) mata pelajaran Pendidikan Islam KSSM bagi MBK MaL.

Seterusnya adalah kajian daripada Christopher Ryan Wagar (2016), The Impact of Audiobooks on Reading Comprehension and Enjoyment. Tahap kesedaran membaca dalam kalangan pelajar yang sememangnya sangat rendah adalah faktor kajian ini dilakukan. Oleh yang demikian, kajian ini meneliti sama ada teknologi audiobooks boleh mempengaruhi kemahiran pemahaman pelajar dan tahap keseronokan membaca. Kajian ini menggunakan kaedah soal-selidik dengan 
menyediakan satu set soalan untuk menentukan sama ada pengajaran yang diterapkan dengan teknologi audiobooks dapat meningkatkan tahap pembelajaran pelajar. Peserta terdiri daripada pelbagai demografi, iaitu umur, kaum, etnik, tahap pendapatan dan kewarganegaraan. Pelajar yang diambil sebagai responden pula akan dibahagikan kepada dua kumpulan, iaitu kumpulan pertama akan menggunakan audiobooks dan teks ketika menganalisis buku Brothers Grimm Fairytale. Kumpulan yang kedua pula hanya diberikan buku teks. Secara kesimpulannya, kajian ini terbukti bahawa teknologi audiobooks adalah merupakan satu strategi yang berdaya maju untuk membantu pelajar dalam meningkatkan kemahiran pemahaman bacaan dan keseronokan membaca.

Jeff Whittingham, Stephanie Huffman, Rob Christensen \& Tracy McAllister (2013), menemukan kegunaan audiobooks yang bergelut mempunyai kesan positif terhadap kemahiran membaca dan sikap terhadap membaca. Penemuan ini penting memandangkan kekurangan penyelidikan secara langsung yang berkaitan dengan kesan audiobooks, walaupun penggunaan audiobooks yang tersebar luas.

Perbincangan oleh Rusnajaa (2018), dalam blog mukasurat.my memperkatakan bahawa Jabatan Psikologi Bereksperiman dari University of College London (UCL) di United Kingdom dengan kerjasama Audible, iaitu sebuah anak syarikat Amazon telah melakukan kajian terhadap 103 peserta yang berumur dalam lingkungan 18 tahun hingga 67 tahun dalam melihat perubahan gaya penceritaan daripada pelbagai media. Berdasarkan penulisan tersebut, kajian yang menggunakan kaedah soal selidik dan sensor biometrik Empatica E4 terhadap peserta bagi mendapatkan aktiviti elektrokimia kulit telah menemui hasil pendengaran terhadap buku audio meningkatkan kadar degupan jantung dan respon otak. Di samping itu, kajian ini juga membuktikan bahawa naratif bersuara memainkan peranan besar dalam menarik minat pendengar buku audio. Rumusannya, kajian ini menjelaskan bahawa penceritaan melalui buku audio menghasilkan tindak balas emosi dan fisiologi yang lebih kuat, degupan jantung yang lebih laju dan suhu badan meningkat. Jelaslah format buku audio memberikan ruang kepada pengkarya mengawal emosi-emosi pendengar mereka.

Artikel yang ditulis oleh Joel R. Montgomery (2009), Using Audiobooks to Improve Reading and Academic Performance juga merupakan sorotan kajian yang boleh didapati mengenai buku audio. Kajian ini adalah bagi mengkaji faktor yang mempengaruhi minat membaca dan meningkatkan pemahaman dalam kalangan pelajar sekolah menengah. Oleh yang demikian, pelajar akan diuji tahap kefahaman dengan menggunakan buku audio bagi pelajar aliran bahasa Inggeris (EEL) dan bagi penutur bahasa Inggeris asli (NES). Secara keseluruhan, penggunaan buku audio ini dapat meningkatkan prestasi membaca dan akademik bagi pelajar bahasa Inggeris (ELL) dan untuk penutur bahasa Inggeris asli (NES) tersebut.

Berdasarkan sorotan kajian di atas, secara ringkasnya dapat dirumuskan bahawa perkembangan buku audio kesusasteraan Melayu masih belum diperkatakan secara meluas di Malaysia. Jika adapun hanya perbincangan secara umum sahaja, seperti tentang Kesan Perkembangan Teknologi terhadap Industri Penerbitan Buku di Malaysia oleh kajian Fadli Abdullah dan Md Sidin Ahmad Ishak (2016), Rosmani Omar dan Siti Ezaleila Mustafa (2017), Buku Digital Interaktif Kanak-Kanak di Malaysia: Platform untuk Penerbit Mengupayakan Pembangunan Kandungan Kreatif Negara dan Priyanto, I. \& Sedyaningsih, S. (2013), Buku digital: Kajian literature perkembangan dan pengaruhnya pada perpustakaan. Kajian-kajian tentang buku audio tertumpu kepada keberkesanan buku audio dalam meningkatkan pemahaman dan keseronokan 
dalam pembelajaran dan pengajaran. Daripada kajian-kajian tersebut, didapati bahawa buku audio berkemampuan mempertingkatkan pemahaman dan menarik minat pelajar dalam meneliti sesebuah karya. Justeru itu, kajian ini merupakan langkah permulaan bagi memperlihatkan senario perkembangan buku audio terutama dalam bidang sastera Melayu di Malaysia.

\section{Metodologi Kajian}

Kajian tentang buku audio (audiobooks) sastera sebagai alternatif pembacaan karya sastera dalam era digital ini menggunakan kaedah kajian kepustakaan dan kajian lapangan. Kajian kepustakaan dilakukan untuk meneliti bahan-bahan bacaan serta mengakses buku-buku audio pilihan yang terdapat dalam talian, sama ada dalam laman sesawang organisasi ataupun melalui aplikasi-aplikasi yang tertentu. Kajian lapangan pula dilakukan dengan mengunjungi syarikat penerbitan serta menemubual pemilik syarikat penerbitan buku audio bagi mendapat maklumat secara terperinci tentang penerbitan dan sambutan terhadap buku audio. Kedua-dua kaedah ini dapat mengumpul maklumat secara terperinci tentang keberadaan buku audio di pasaran.

\section{Sejarah dan Perkembangan Buku Audio}

Pada dasarnya, audiobooks mula diperkenalkan sejak awal lagi, iaitu pada tahun 1877 apabila diperkenalkan alat perakam pertama, iaitu fonograf oleh Thomas Edison. Beliau membaca dan merakam Mary had a little lamb yang dikatakan bacaan kanak-kanak pertama. Kemudian, alat rakaman Thomas Edison telah dibaik pulih oleh Alexander Graham Bell pada tahun 1880, yang dikenali sebagai grapaphone. Pada tahun 1890-an pula, Emile Berliner telah mengambil langkah pertama dengan memperkenalkan flat discs, iaitu transformasi daripada fonograf kepada gramophone (Aram Mrjoian, 2016).

Antara tahun 1930 dan 1950-an pula, The Library of Congress telah membuat pelaburan dalam projek yang dinamakan "Books for the Adult Blind Project". Rakaman terawal termasuklah buku Hellen Keller, kitab Injil, O. Henry dan Edgar Allen Poe. Ramai askar mendapat kecederaan mata semasa Perang Dunia Pertama dan Kedua, dan kemudian itu terdapat kesedaran untuk membantu askar pencen dan rakyat Amerika Syarikat yang cacat penglihatan untuk mendapat akses kepada buku dalam bentuk audio. Dalam usaha membantu askar-askar yang buta, kumpulan Women's Auxiliary di Perpustakaan New York yang diketuai Anne T. MacDonald menubuhkan organisasi Recording for the Blind. Organisasi ini menggunakan studio untuk merakam pembacaan buku teks untuk askar pencen dan orang awam yang memerlukan rakaman tersebut untuk pendidikan (Aram Mrjoian, 2016).

Pada tahun 1952, Caedmon Records telah menghasilkan salah satu buku audio terawal yang terkenal, iaitu sebuah pembacaan oleh Dylan Thomas. Bahagian A mengandungi koleksi puisinya, manakala Bahagian B ialah rakaman pembacaan A Child's Christmas in Wales. Hari ini, Caedmon Records adalah sebahagian daripada syarikat Harper Collins. Tahun 1960-an mula menampakkan kemajuan teknologi, iaitu muncul pita-pita rakaman yang memuatkan rakaman-rakaman buku audio diperkenalkan di United Kingdom (UK). Cara penggunaannya bersifat manual; pendengar perlu memutar pita rakaman sebelum dapat mendengar cerita. Namun begitu alat ini mempunyai 
kelemahannya juga, antaranya menyukarkan golongan OKU penglihatan untuk menggunakannya serta alat ini lebih berat berbanding dengan buku audio terdahulu. Ia juga melambatkan proses penghantaran kerana perlu dihantar secara berasingan disebabkan strukturnya. Apabila kaset mula diperkenalkan pada akhir 1960-an, masalah-masalah tersebut dapat diatasi kerana pita rakaman, kaset audio mudah diakses dan lebih ringan bentuknya. Oleh yang demikian, buku yang dihasilkan dalam bentuk audio sebegini telah mendapat perhatian daripada perpustakaan-perpustakaan awam di Amerika Syarikat dan United Kingdom untuk disusun seiring dengan buku-buku bercetak yang sedia ada. Antara lain, syarikat penerbitan juga telah merebut peluang dengan menghasilkan buku berbentuk audio yang seiring dengan buku bercetak.

Perkembangan audiobooks semakin mendapat perhatian dalam kalangan masyarakat sejagat. Jika dahulunya, audiobooks direka untuk menepati kehendak golongan kurang upaya, namun sekitar tahun 1970-an, pasaran penjualan audiobooks semakin meningkat. Selain dijual di pasaran, audiobooks dalam bentuk kaset turut disewakan untuk kegunaan para pemandu serta pengguna jalan raya yang kian meningkat pada ketika itu. Fenomena ini semakin berlarutan dan diterima baik dalam kalangan masyarakat apabila Compact Disk (CD) mula diperkenalkan sekitar tahun 1982. Tambahan pula, era 1990-an adalah era kegemilangan dengan penghasilan audiobooks bagi setiap karya popular dalam bentuk CD. Ekoran dengan penjualan audiobooks yang semakin meningkat di pasaran, satu aplikasi digital "Audible" diperkenalkan pada tahun 1995 (Aram Mrjoian, 2016).

Pada tahun 1977 Persatuan Penerbit Audio (APA) dibentuk untuk menjaga kepentingan bersama pengeluar buku audio, pengedar serta pembekal yang berkaitan, dan pada masa ini terdapat lebih daripada empat puluh penerbit dengan keahlian dalam APA (Maria Cahill \& Jennifer Moore, 2017, p. 23).

Perkembangan peralatan teknologi telah meningkatkan penjualan buku audio melalui kaedah dalam talian, iaitu para penerbit buku dapat menghasilkan lebih banyak buku digital dan buku audio. Penerbitan buku-buku audio semakin meluas apabila karya-karya audio ini boleh diakses dengan mudah melalui peranti elektronik tanpa mengira masa dan mesra pengguna melalui laman sesawang buku audio, di peranti Apple, Android, Windows, dan sebagainya.

Jika dilihat perkembangannya di Malaysia, terdapat rakaman-rakaman buku oleh syarikat penerbitan atau institusi-institusi yang tertentu. Misalnya pada tahun 2018, Universiti Putra Malaysia (UPM) telah melancarkan projek buku audio untuk membantu golongan orang kelainan upaya $(\mathrm{OKU})$ penglihatan yang memerlukan bahan bacaan untuk merangsang perkembangan mental, ilmu dan minat membaca. Aplikasi ini juga merupakan salah satu usaha untuk meningkatkan kemampuan OKU melalui teknologi maklumat dan bercirikan mesra OKU penglihatan, dengan fungsi arahan suara dan teknik penggunaan 'swipe' dan 'tap' yang mudah (Nur Zila Zainuddin, 2018, p. 4).

Selain itu, terdapat syarikat-syarikat yang giat menerbitkan buku audio berbahasa Melayu dan bahasa Inggeris, antaranya seperti Nusantara Audiobooks, Tlinge Beta dan Kindle Malaysia. Di samping itu, institusi, organisasi atau penerbit buku seperti Perpustakaan Negara Malaysia, Karangkraf E-Mall dan Kinokuniya juga ada menyediakan pelbagai buku audio sebagai pilihan kepada masyarakat. Buku-buku ini boleh dibeli terus dalam talian dengan harga yang telah ditetapkan. Pembaca disediakan dengan "preview book" untuk memilih buku-buku yang sesuai. 
Syarikat buku audio yang popular dan terbesar di dunia pada hari ini pula ialah Audible, sebuah syarikat milik Amazon, yang menerbitkan pelbagai genre buku audio serta memberikan akses percuma selama sebulan untuk pendaftaran sebagai ahli. Selain itu, penerbitan ini juga menawarkan pelbagai promosi dari semasa ke semasa bergantung kepada situasi semasa. Misalnya, baru-baru ini pihak Audible menawarkan khidmat streaming audiobooks kepada kanak-kanak dan remaja secara percuma sepanjang kuarantin pada musim Covid-19.

Dengan adanya pelbagai syarikat penerbitan buku audio sememangnya menyediakan pelbagai pilihan dan kepelbagaian genre buku audio mengikut selera pembaca. Kemudahan untuk mengakses buku audio juga menjadi lebih mudah dan mesra pembaca dengan adanya perkembangan peralatan elektronik dan teknologi kini. Hanya dengan 1 klik sahaja pembaca boleh menikmati karya kegemaran masing-masing.

\section{Nusantara Audiobooks Pembacaan Alternatif Karya Sastera}

Nusantara Audiobooks telah ditubuhkan pada suku tahun kedua 2017 dan masih beroperasi sehingga kini. Nusantara Audiobooks ialah platform yang menawarkan buku audio yang berbahasa Melayu, bahasa Inggeris dan Indonesia dan mengangkat karya-karya agung atau klasik yang bersifat nusantara. Buku audio dikategorikan sebagai buku audio tempatan pertama di Malaysia. Melalui cogan kata yang dipegang, iaitu "Listen, Anytime, Anywhere”.

Idea penubuhan Nusantara Audiobooks bermula daripada sembang santai antara tiga orang sahabat yang mempunyai impian bersama, yang akhirnya membuahkan hasil yang bermanfaat untuk masyarakat sejagat. Hasrat mereka ini diterima baik oleh pihak kerajaan negeri Selangor, iaitu menjalinkan kerjasama bersama antara kerajaan negeri Selangor, iaitu Agenda Siri Pencerahan atas usaha sama bersama Dato Azmin Ali (mantan Menteri Besar Negeri Selangor) dan juga Perbadanan Perpustakaan Negeri Selangor (PPAS). Hasil kerjasama ini menjadikan impian serta cita-cita pendengar tegar buku audio, iaitu Fikri Faisal atau pengarah ini sendiri menjadi kenyataan.

Awal kemunculan Nusantara Audiobooks, telah memilih 15 buah buku daripada karya kesusasteraan agung atau klasik tempatan. Dalam tempoh dua tahun yang baru-baru ini, Nusantara Audiobooks telah menerbitkan kira-kira 60 buah buku audio. Karya-karya agung yang dirakam antaranya datang dari negara nusantara seperti Brunei, Singapura, Indonesia serta Malaysia. Pemilihan karya oleh pihak Nusantara adalah melalui perbincangan dan persetujuan daripada pelbagai pihak.

In 2017, Nusantara Audiobooks, the pioneering audiobook platform in Malaysia, was born. The company has since produced over 60 audiobooks, both fiction and non-fiction, in English, Bahasa Malaysia and Bahasa Indonesia.

(Terence Toh, 2020) 
Nusantara Audiobooks merupakan perintis kepada syarikat penerbitan buku audio tempatan di Malaysia sudah tentu menghadapi pelbagai cabaran dan kesukaran dalam penerbitan buku-buku audio. Namun kesemua ini dapat diatasi dengan sokongan daripada semua pihak. Antaranya dalam memilih seorang pencerita atau narator bukanlah hal yang mudah apabila melibatkan emosi untuk membaca dan meneruskan pembacaan yang sekata suaranya. Kesinambungan suara dan mood untuk membaca karya-karya itu dikira berjaya. Antara narator atau pembaca buku audio yang telah menjadi sebahagian daripada keluarga Nusantara Audiobooks ini seperti Wan Hanafi Su, Budi Citawan, Tengku Elida, Adibah Noor, Nadia Khan, Allahyarham Mahadzir Lokman, Kudsia Kahar, Oki Rusmini, Tio Pakusadewa, Airil Razali, Mohd Eekmal Ahmad, Ustaz Najmi, Dato M Nasir, Faiz Abdullah, Tan Sri Khoo Kay Kim. Ayu Utami, seorang penulis yang sangat dikenali di Indonesia juga telah menjadi sebahagian daripada pembaca yang dijemput oleh Nusantara Audiobooks untuk menjadi narator dan membaca karyanya sendiri. Keupayaan narator untuk membaca dalam mood yang konsisten dikategorikan sebagai narator yang terbaik. Pemilihan narator yang dilihat dalam oleh pihak Nusantara Audiobooks ialah pemilihan karya atau buku melihat kepada tema cerita, umur yang bersesuian, serta jantina narator. Mengikut kepada ciri-ciri utama untuk pemilihan narator, iaitu umur yang bersesuian untuk menjadi narator ialah seperti contoh karya agung Hikayat Abdullah yang dibacakan teksnya ialah pelakon veteran yang masih segak bergaya, iaitu Wan Hanafi Su. Berdasarkan suara yang tegas dan mempunyai keupayaan dalam membacakan patah perkataan satu persatu memberi kelebihan kepada Wan Hanafi Su untuk membacakan karya Melayu klasik tersebut. Ayu Utami, seorang penulis dan juga seorang narator yang membacakan sendiri karyanya memberi jiwa dalam pembacaan karyanya sendiri.

Nusantara Audiobooks, memilih karya-karya agung atau klasik kerana mengikut perbincangan daripada pihak Nusantara bersama pihak kerajaan Negeri Selangor serta Perbadanan Perpustakaan Awam Selangor (PPAS) untuk meneruskan Agenda Pencerahan Selangor yang telah menetapkan bahawa karya-karya agung menjadi pilihan untuk dijadikan buku audio. Oleh kerana itu, usaha itu disambut baik Nusantara Audiobooks yang memang mahu mengangkat karya-karya agung sebagai medan utama mereka berkarya. Karya-karya agung mempunyai keunggulannya tersendiri yang boleh mempersonakan khalayaknya. Dalam membincangkan tentang keunggulan karya, Fauzi Hassan, Tengku Intan Marlina Tengku Mohd. Ali \& Madiawati Mamat@Mustaffa (2019, p. 35) menjelaskan bahawa terdapat unsur-unsur magis dan sihir yang akan segera larut dalam diri khalayak. Khalayak berada dalam keasyikan fizikal dan metafizikal yang terjadi hasil kebijaksanaan mencerna struktur forma lteks dengan imbangan komposisi sehingga terkesan dengan sifat-sifat artistiknya. Terdapat nilai-nilai kemanusiaan dan moraliti zamannya di dalamnya serta terlihat kekuatan intensifikasi teksnya. Justeru, karya-karya yang mempunyai nilai-nilai persona yang tinggi perlu diterbitkan dalam pelbagai bentuk, antaranya bentuk rakaman yang telah diusahakan oleh pihak Nusantara Audiobooks.

Semangat dan matlamat lima orang bersaudara ini ialah mahu membuka mata masyarakat bahawa masih ada alternatif lain untuk menambah ilmu pengetahuan selain membaca, iaitu dengan mendengar buku. Hal ini, kebanyakan pembaca akan mengambil masa senggang untuk membaca manakala dengan mendengar ini, masa akan lebih terisi dengan hanya mendengar buku audio. Pembacaan dengan mendengar boleh dilakukan di mana-mana sahaja sama ada dalam kenderaan atau sambil melakukan kerja-kerja harian. Walaupun Nusantara Audiobooks baru sahaja berkecimpung dalam masa dunia penerbitan buku audio, namun telah ramai yang menyambut baik idea bernas ini. 
Cara serta teknik pihak Nusantara Audiobooks melancarkan serta mempromosikan Nusantara Audiobooks ini dengan mengaktifkan akaun laman seperti Facebook, Instagram dan Twitter hanya untuk memperkenalkan kepada khayalak akan keberadaan mereka dalam zaman sekarang. Di samping itu, pihak Nusantara juga telah mengunjungi beberapa acara yang berkaitan seperti Pesta Buku Antarabangsa Kuala Lumpur 2019 yang disambut meriah baru-baru ini di PWTC. Para narator yang terlibat juga ada mempromosikan Nusantara Audiobooks melalui laman sesawang milik mereka sendiri.

Sekarang, Nusantara Audiobooks masih mengekalkan promosi mereka dengan memberi promosi percuma kepada pengguna yang baru mendaftar dengan Nusantara Audiobook ini. Kini, Nusantara Audiobooks boleh didapati di Apss Store untuk pengguna telefon pintar jenis Apple, manakala pengguna telefon android boleh didapati di google play store untuk menjadi pengguna Nusantara Audiobooks.

Kelebihan dan keistimewaan yang dijadikan sebagai kebaikan untuk pendengar tegar Nusantara Audiobooks ialah kandungan atau buku-buku yang dipilih ialah karya-karya agung atau klasik. Buku audio Nusantara juga memilih kandungan buku bahasa Melayu untuk mencipta kelainan lain daripada lain. Namun, atas tuntutan kehendak pendengar mereka kini memilih untuk menerajui pasaran dunia dengan memilih kandungan yang berbentuk bahasa Inggeris. Demi menarik minat golongan muda, Nusantara Audiobooks sudah menambah kandungan terbaharu, iaitu dari aspek genre yang berlainan. Pihak Nusantara Audiobooks telah memilih untuk berkolabrasi dengan beberapa syarikat buku seperti syarikat buku Fixi dan juga Dubook. Karya pertama yang telah dipilih atas pilihan pendengar ialah Gantung oleh Nadia Khan. Malah, Nadia Khan juga telah berbesar hati untuk menjadi narator karyanya sendiri. Kini, Nusantara AudioBooks sedang memilih untuk menerbitkan buku audio karya-karya berbentuk indie untuk menerajui pasaran yang seterusnya. Nusantara Audiobooks juga bercita-cita untuk mengambil buku penterjemahan sebagai bahan atau karya yang terbaru.

Sasaran khalayak buku audio terbitan syarikat Nusantara Audiobooks ini kepada golongan orang kelainan upaya $(\mathrm{OKU})$ penglihatan, kelompok yang sudah bersara dan juga golongan muda yang tidak mempunyai masa untuk membuka buku dan membaca setiap helai dalam sebuah buku. Oleh itu, buku audio masih memberi promosi kepada pengguna yang baru sahaja mendaftar di aplikasi Nusantara. Harga jualan buku audio bermula daripada RM25 untuk sebuah buku.

Antara buku yang telah dipilih oleh buku audio Nusantara ialah Salina dan Langit Petang, karya A. Samad Said, Hikayat Abdullah oleh Abdullah Munsyi, Tenggelamnya Kapal Van Der Wijck oleh Hamka, Sejarah Melayu oleh Tun Sri Lanang, Mitos Pribumi Malas dan Kita dengan Islam oleh Syed Hussein Al- Attas. Buku-buku dari Indonesia pula, antaranya $A k u$ oleh Chairil Anwar, Saman oleh Ayu Utami, Larung dan Tempurung. Antara koleksi buku bahasa Inggeris pula ialah No Harvest But Thorn (Terjemahan daripada karya Ranjau Sepanjang Jalan oleh Shahnon Ahmad).

Pada peringkat awal, pihak Nusantara Audiobooks merakamkan karya-karya sastera adalah berdasarkan karya-karya sastera yang diiktiraf sebagai karya agung dan daripada penulis-penulis yang besar serta terkenal seperti Shahnon Ahmad, A.Samad Said dan Abdullah Munsyi. Seterusnya pemilihan karya juga dipilih berdasarkan khalayak, iaitu pemilihan karya-karya seperti Siri Sang Kancil adalah untuk menarik minat khalayak kanak-kanak untuk meneliti karya secara rakaman. 
Cabaran serta rintangan buku audio Nusantara ini semestinya ada. Tambahan lagi mereka ini platform yang pertama di Malaysia. Rintangan utama yang telah dilalui oleh buku audio Nusantara untuk mengekalkan kos yang berpatutan. Bagi mengekalkan kos yang berpatutan, buku audio perlu memikirkan pemilihan buku yang menjadi pilihan pendengar atau masyarakat zaman sekarang. Seterusnya, mengubah persepsi penerimaan masyarakat kini. Hal ini berkaitan juga kepada promosi yang dilakukan oleh pihak buku audio Nusantara sendiri. Promosi hendaklah berterusan dan terus menerajui ke pasaran yang lebih tinggi. Sokongan dan dorongan daripada pelbagai pihak seperti pihak kerajaan negeri Selangor atau pihak kerajaan negeri lain, pihak institusi awam dan swasta, pihak sekolah yang berkaitan serta daripada sektor kerajaan juga sektor swasta untuk mengambil peduli akan inisiatif yang sedang dilakukan ini.

Hala tuju Nusantara Audiobooks adalah ingin menerajui penerbitan buku audio ke pasaran antarabangsa dan dikenali serta dijadikan sebagai salah satu rujukan untuk yang memerlukan. Hasrat ini akan tercapai sekiranya pihak Nusantara Audiobooks mendapat sokongan serta dorongan daripada pelbagai pihak termasuklah golongan pembaca dan pemerintah. Bilangan buku rakaman tempatan akan bertambah serta pengisian kandungannya juga mampu menarik perhatian pendengar.

Umumnya semua pihak perlu berganding bahu untuk terus kekal berada dalam satu aliran berbentuk pendidikan kepada masyarakat masa kini. Adalah menjadi harapan pihak Nusantara Audiobooks, agar dapat memperbanyakkan bilangan buku audio berada di Malaysia. Hal ini untuk memberi kesedaran kepada masyarakat bahawa buku audio telah menjadi medan utama pembaca mendengar buku yang dibaca oleh narator yang terpilih menggunakan karya-karya yang bermutu tinggi ilmunya.

\section{Kelebihan Buku Audio Sastera sebagai Pembacaan Alternatif}

Perkembangan teknologi maklumat yang sedia ada kini, membolehkan sesuatu bidang ilmu diketengahkan dan dikongsi kepada khalayak ramai tanpa adanya batasan. Pelbagai aplikasi platform yang menggunakan elemen multimedia pastinya menarik perhatian ramai untuk menggunakannya, lebih-lebih lagi dengan kesibukan dan kekangan waktu bagi melakukan sesuatu perkara akibat tuntutan pekerjaan, aktiviti harian dan bermacam-macam lagi. Namun begitu, kesibukan dengan tugas harian menjadi penghalang untuk kita untuk membaca. Perubahan corak pembacaan daripada buku fizikal kepada buku rakaman telah memudahkan pembaca untuk mendengar pembacaan terutamanya karya-karya yang berbentuk kreatif. Corak membaca telah berubah mengikut konteks peredaran zaman. Pembacaan secara audio boleh berlaku tanpa mengira masa dan tempat.

Buku audio atau buku rakaman mempunyai pelbagai kelebihan yang boleh dimanfaatkan oleh pembaca. Pertama, pada dasarnya, buku audio bertujuan membantu golongan orang kelainan upaya (OKU) penglihatan untuk mendapatkan pelbagai maklumat. Melihat pada sejarah perkembangan buku audio itu sendiri, inisiatif kepada terhasilnya buku bercorak audio ini dilihat mampu membantu golongan tersebut menerima sesuatu maklumat sama seperti golongan manusia biasa. Memang tidak dapat dinafikan bahawa kaedah bacaan Braille turut dapat membantu OKU penglihatan membaca, tetapi kaedah ini memerlukan usaha dan kerahan tenaga individu OKU itu sendiri bagi menyentuh abjad-abjad pada braille dan semestinya ini akan memakan masa yang agak lama untuk menghabiskan bacaan satu buku. Dengan kewujudan buku audio, seseorang OKU 
penglihatan tersebut boleh mengakses bacaan dengan mendengar rakaman suara tukang pencerita. Kepentingan penggunaan buku audio untuk golongan ini juga dapat dilihat dengan pelbagai usaha yang dilakukan oleh pelbagai pihak untuk membangunkan pelbagai projek buku audio. Antara seperti yang dilakukan oleh unit info-tech Tsis Taekwang Group Korea, yang mengumumkan pada 27 Julai 2014 bahawa ia telah memberikan sokongan untuk memulakan "Projek Pembangunan Aplikasi Buku Audio" dengan Persatuan Bagi Kebajikan OKU Cacat Penglihatan Korea. Apabila projek itu selesai, mereka yang kurang upaya penglihatan akan dapat menikmati pelbagai kandungan dengan hanya menggunakan telefon pintar, dan bukannya membuat perjalanan ke perpustakaan Braille (J. H. Kim, 2014).

Kedua, buku audio turut dilihat bermanfaat bagi menggalakkan dan menyemai sikap suka membaca dalam kalangan kanak-kanak. Seperti yang kita sedia maklum, 'jika ingin melentur buluh, biarlah dari rebungnya' maka bersesuaian dengan wujudnya buku audio yang dicetak ini yang memuatkan kisah-kisah tauladan mampu menjana dan mengembangkan penguasaan bahasa kanak-kanak itu sendiri. Menurut Rosmani Omar dan Siti Ezaleila Mustaffa (2017, p. 183), penerbitan buku kanak-kanak interaktif merupakan platform untuk para penerbit di Malaysia mengupayakan pembangunan kandungan kreatif negara. Bahan pengajaran berbentuk interaktif dikatakan sangat baik untuk dijadikan bahan tambahan oleh guru di samping banyak memberikan kesan dalam pembangunan literasi awal, kefahaman membaca dan pembangunan bahasa untuk kanak-kanak.

"...in the UK, of the 14 million units sold, approximately $18 \%$ were for children.5 More recently, a report issued by the Insight People found that since January 2018, as smart speaker consumption by children has increased, audiobook popularity has increased by $138 \%$, with over $34 \%$ of children listening to audiobooks for 15 minutes a week".

(Emily Best, 2020, p. 2)

Kesedaran mengenai kepentingan buku audio meningkat dalam golongan kanak-kanak kerana pelbagai kemahiran dapat dimanfaatkan daripada pembacaan buku ini. Antaranya, buku audio turut mengasah kemahiran mendengar seorang kanak-kanak, iaitu memanfaatkan pancaindera pendengaran mereka serta melatih mereka mengenali kepelbagaian nada suara mengikut emosi yang terkandung dalam sesebuah penceritaan. Mendengar buku audio turut menepati kehendak kanak-kanak. Hal ini kerana sifat kanak-kanak yang lebih cenderung aktif dalam mendengar cerita berbanding membaca buku cerita itu sendiri. Golongan ibu bapa juga boleh memanfaatkan penggunaan buku audio untuk menemani anak-anak mereka dalam aktiviti membaca bagi menambahkan pengetahuan am. Bagi golongan ibu bapa yang sibuk bekerja, mereka tidak lagi boleh menjadikan pekerjaan mereka sebagai alasan bahawa mereka tiada masa untuk bersama-sama anak mereka. Justeru buku audio bertindak sebagai "win-win situation", baik pada kanak-kanak tersebut mahupun ibu bapanya.

Ketiga, buku audio ini turut boleh diraih manfaatnya oleh khalayak ramai. Alternatif mendengar sesebuah cerita melalui aplikasi-aplikasi yang sedia ada dan mudah diakses pada hujung jari ini, mampu melatih masyarakat berjinak-jinak dengan dunia teknologi maklumat. Tidak ada istilah ketiadaan masa lagi yang boleh dijadikan alasan bagi seseorang itu mengisi ilmu pengetahuan hanya dengan menggunakan cara konvensional, iaitu membaca buku bercetak. 
Seiring dengan peredaran zaman yang menuju ke arah penggunaan teknologi secara menyeluruh, buku audio dilihat sebagai alternatif yang baik dalam mengekalkan dan menyemai amalan suka membaca. Penggunaan yang mudah, ringan dan boleh diakses di mana sahaja dan pada bila-bila masa sahaja bakal mencetuskan fenomena masyarakat yang bukan sahaja berjaya dalam kerjaya mereka, bahkan juga dapat menambah pengetahuan dan mengisi masa lapang mereka menerusi buku audio.

Selain itu, buku audio memberi satu pengalaman baharu kepada golongan pembaca menikmati sesebuah cerita dengan elemen digital suara. Pemilihan pencerita atau narrator juga amat penting. Selain penghayatan dan pemahaman terhadap isi cerita, seseorang pencerita perlu menyampaikan cerita dalam pelbagai situasi mengikut tema dan penceritaan yang dibacanya. Keberkesanan sesebuah buku audio bukan sahaja terletak kepada pengisian karya, tetapi juga kebijaksanaan pencerita memainkan mood pendengar atau pembaca. Penggunaan audio yang baik juga menyumbang kepada perkembangan penggunaan buku audio agar kekal relevan dan turut seiring dengan buku buku bercetak yang sedia ada di pasaran.

\section{Kesimpulan}

Secara umumnya dapat dikatakan bahawa buku audio telah lama berada di pasaran dan mempunyai kepentingannya yang tersendiri sama ada kepada golongan orang kelainan upaya (OKU) penglihatan, pelajar, kanak-kanak dan masyarakat yang tidak mempunyai masa untuk membaca buku secara fizikal. Buku audio memberi satu pengalaman baharu kepada golongan pembaca menikmati sesebuah cerita dengan elemen audio pelbagai emosi daripada pencerita (narator) yang professional. Sifatnya juga yang mesra pembaca dan mudah diakses menjadikan buku ini sebagai bahan pembacaan alternatif yang boleh dimanfaatkan bersama. Buku audio telah berkembang pesat dan diketahui umum.

Namun, buku-buku audio sastera Melayu masih lagi pada peringkat awal dan perlu dipergiatkan penerbitannya dan dihebahkan kepada masyarakat umum agar dapat dimanfaatkan bersama. Karya-karya sastera yang tinggi nilainya perlu diterbitkan dalam pelbagai medium agar mendekatkan karya sastera kepada masyarakat. Usaha yang dilakukan oleh pihak Nusantara Audiobooks perlu menjadi ikutan syarikat-syarikat penerbitan atau organisasi yang menerbitkan buku-buku audio agar memperbanyakkan terbitkan buku audio sastera Melayu. Nusantara Audiobooks bukan sahaja menerbitkan buku-buku audio untuk tujuan keuntungan semata-mata, tetapi juga mengangkat karya-karya agung tempatan selari dengan perkembangan teknologi dalam era digital ini. Pelbagai genre sastera diterbitkan dalam bentuk buku rakaman bagi menyediakan kepelbagaian pembacaan kepada khalayak pembaca. Keberadaan buku audio sastera Melayu perlu diperluaskan lagi sebagai bentuk alternatif pembacaan kepada khalayak buku supaya akhirnya masyarakat kita tidak lagi mempunyai alasan untuk tidak membaca.

Penyelidikan ini juga merupakan bantuan Geran Penyelidikan Universiti (RU)-Falkulti Program GPF006K-2018. 
Buku Audio Sastera Sebagai Alternatif Pembacaan Karya Sastera Dalam Era Digital

\section{Rujukan}

Baskin, Barbara H., \& Karen Harris. (1995). Heard any good books lately? The case for audiobooks in the secondary classroom. Journal of Reading, pp. 372- 376.

Best, Emily. (2020). Audiobooks and literacy: A rapid review of the literature. A National Literacy Trust Research Report, pp. 1-13. Retrieved from https://files.eric.ed.gov/fulltext/ED607775. pdf.

Burkey, Mary. (2009). Long-Form Listening. Book Links 18.6, 26-27. Retrieved from http://www. audiopub.org/resources/Burkey_BookLinks2009.pdf.

Cahill, Maria \& Moore, Jennifer. (2017). A sound history: Audiobooks are music to children's ears. Journal of the Association for Library Service to Children. (ALSC) Vol. 15, No 1.

Casbergue, Renee Michelet \& Karen H. Harris. (1996). Listening and literacy: Audiobooks in the reading program. Reading Horizons. Vol. 37, 48-59. Retrieved from https://www.audiopub. org/resources.

Cardillo, Arnie, et al. (2007). Tuning in to audiobooks: Why should kids listen? Children and Libraries, pp. 42-46. Retrieved from http://www.audiopub.org/resources/Cardillo_ CAL2007.pdf.

Chen, Shu-Hsien L. (2004). Improving readers skills through audiobooks. School Library Media Activities Monthly, pp. 22-25. Retrieved from https://www.audiopub.org/resources.

Fadli Abdullah \& Md Sidin Ahmad Ishak. (2016). Kesan perkembangan teknologi terhadap industri penerbitan buku di Malaysia. Jurnal Pengajian Media Malaysia, 18 (2), 71-86.

Fauzi Hassan, Tengku Intan Marlina Tengku Mohd Ali \& Madiawati Mamat@Mustaffa (2019). Subjektiviti dalam novel-novel terpilih Faisal Tehrani. Jurnal Pengajian Melayu/ Journal of Malay Studies (JOMAS), Jil. 30, 28-52.

Whittingham, J. L., \& Huffman, S, Christensen, R \& McAllister, T. (2013). Use of Audiobooks in a School Library and Positive Effects of Struggling Readers' Participation in a LibrarySponsored Audiobook Club. School Library Research: Research Journal of the American Association of School Librarians. Vol. 16, 1-18.

J. H. Kim. (2014). Audiobook app for visually impaired to be made by Korea's top fiber maker. The Korea Bizwire. Retrieved from http://koreabizwire.com/.

Montgomery, J.R. (2009). Using audiobooks to improve reading and academic performance. Arlington, Va.: ERIC Document Reproduction Service, ED Working Paper”.

Moody, Kate. (1989). Audio tapes and books: Perfect partners. School Library Journal 35.6 (1989), 27- 29. Retrieved from http://www.audiopub.org/resources.

Mrjoian, A. (2016). A brief a story of the audiobooks. 28 Jun 2016. Retrieved from https://bookriot. com/a-brief-history-of-the-audiobook/.

Nurutthoilah Mohd Nabil et al. (2018). Pembangunan perisian interaktif audio buku pendidikan Islam sekolah menengah kebangsaan (i-TALK PISMEN): Satu Kajian Keperluan Bagi Murid Berkeperluan Khas Masalah Penglihatan dalam International Journal for Studies on Children, Women, Elderly and Disabled, Vol. 4, 81-88.

Nur Zila Zainuddin. (2018). UPM lancar projek buku audio untuk OKU penglihatan. Tribun Putra. April - Jun 2018. Retrieved from http://www.tribunputra.upm.edu.my.

Priyanto, I. \& Sedyaningsih, S. (2013). Buku digital: Kajian literature perkembangan dan pengaruhnya pada perpustakaan. Fihris, 8 (2), 1-12. Retrieved from http://www.academia. edu/7400472/Buku_Digital_Kajian_Literatur_Perkembangan_dan_pengaruhnya_pada_ perpustakaan.

Rosmani Omar \& Siti Ezaleila Mustafa (2017). Buku digital interaktif kanak-kanak di Malaysia:

e ISSN 2735 - 1904

https://doi.org/10.22452/JOMAS.vol32no1.2 
Platform untuk penerbit mengupayakan pembangunan kandungan kreatif negara. International Journal of Education, Psychology and Counseling. Vol. 2 Issues 6 (Disember 2017), 183-201.

Rusnajaa Mohd Yusoff. (2018). Antara buku audio dan filem: Suatu sorotan neurosains. Retrieved from http://mukasurat.my/2018/07/10/antara-buku-audio-dan-filem-suatu-sorotanneurosains/.

Terence Toh. (2020). Don't have time to read books? Nusantara Audiobooks say you can listen to them. The Star. 7 July 2020. Retrieved from https://www.thestar.com.my/lifestyle/ culture/2020/07/07/giving-stories-a-voice--nusantara-audiobooks-aims-to-grow-malaysianaudiobook-market.

Wagar, Ryan Christopher. (2016). The impact of audiobooks on reading comprehension and enjoyment. Columbia Basin College. Retrieved from http://www.researchgate.net. 